\title{
Aggravated Arthritis
}

National Cancer Institute

\section{Source}

National Cancer Institute. Aggravated Arthritis. NCI Thesaurus. Code C27017.

Exacerbation of an arthritic condition. 